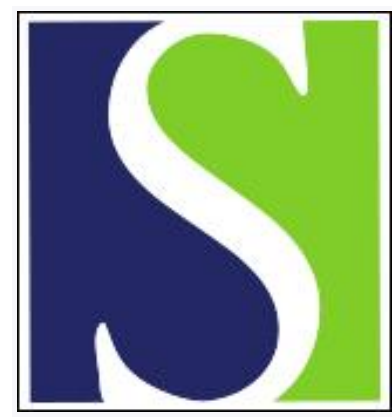

Scand J Work Environ Health 2015;41(2):194-203

https://doi.org/10.5271/sjweh.3482

Published online: 30 Jan 2015, Issue date: 01 Mar 2015

Work schedule and physically demanding work in relation to menstrual function: the Nurses' Health Study 3

by Lawson CC, Johnson CY, Chavarro JE, Lividoti Hibert EN, Whelan EA, Rocheleau CM, Grajewski B, Schernhammer ES, Rich-Edwards JW

Our results indicate a possible role for night work, long working hours, and physically demanding work in menstrual function disturbances, which may have implications for subfertility. This is the first study to find that working rotating and non-rotating nights may have similar effects, and there may be a dose-response effect with the number of nights worked per month.

Affiliation: National Institute for Occupational Safety and Health 1090 Tusculum Ave, MS R-15, Cincinnati, OH 45226, USA. clawson@cdc.gov

Refers to the following texts of the Journal: 1992;18(5):302-309 1999;25(2):144-150

Key terms: circadian rhythm; heavy lifting; long work hours; menstrual cycle variation; menstrual function; night shift work; night work; Nurses' Health Study; Nurses' Health Study 3; physically demanding work; prolonged standing; rotating night shift work; shift work; work schedule

This article in PubMed: www.ncbi.nlm.nih.gov/pubmed/25634477 


\title{
Work schedule and physically demanding work in relation to menstrual function: the Nurses' Health Study 3
}

\author{
by Christina C Lawson, PhD, ${ }^{1}$ Candice Y Johnson, PhD, ${ }^{1,2}$ Jorge E Chavarro, MD, , 4, 5 Eileen N Lividoti \\ Hibert, MA, ${ }^{4}$ Elizabeth A Whelan, PhD, ${ }^{1}$ Carissa M Rocheleau, PhD, ${ }^{1}$ Barbara Grajewski, PhD, ${ }^{1}$ Eva $S$ \\ Schernhammer, MD, 4, 5 Janet W Rich-Edwards, ScD 4, 5, 6
}

\begin{abstract}
Lawson CC, Johnson CY, Chavarro JE, Lividoti Hibert EN, Whelan EA, Rocheleau CM, Grajewski B, Schernhammer ES, Rich-Edwards JW. Work schedule and physically demanding work in relation to menstrual function: the Nurses' Health Study 3. Scand J Work Environ Health. 2015;41(2):194-203. doi:10.5271/sjweh.3482
\end{abstract}

\begin{abstract}
Objectives This study aimed to evaluate occupational exposures and menstrual cycle characteristics among nurses.
Methods Using cross-sectional data collected in 2010-2012 from 6309 nurses aged 21-45 years, we investigated nurses' menstrual function in the Nurses' Health Study 3. We used multivariable regression modeling to analyze the associations between occupational exposures and prevalence of irregular cycles and long and short cycle lengths.

Results The cohort reported cycle length as <21 (1.5\%), 21-25 (15.6\%), 26-31 (69.7\%), and 32-50 (13.2\%) days. In addition, $19 \%$ of participants reported irregular cycles. Working $\geq 41$ hours/week was associated with a $16 \%$ [95\% confidence interval (95\% CI): 4-29\%] higher prevalence of irregular cycles and a higher prevalence of very short (<21-day) cycles [prevalence odds ratio (OR) 1.93, 95\% CI 1.24-3.01] in adjusted models. Irregular menstrual cycles were more prevalent among women working nights only (32\% higher; $95 \%$ CI $15-51 \%)$ or rotating nights (27\% higher, $95 \%$ CI 10-47\%), and was associated with the number of night shifts per month ( $\mathrm{P}$ for trend $<0.0001$ ). Rotating night schedule was associated with long (32-50 day) cycles (OR 1.28, 95\% CI 1.03-1.61). Heavy lifting was associated with a higher prevalence of irregular cycles ( $34 \%$ higher), and the prevalence of cycles $<21$ days and 21-25 day cycles increased with increasing heavy lifting at work ( $\mathrm{P}$ for trend $<0.02$ for each endpoint).
\end{abstract}

Conclusion Night work, long hours, and physically demanding work might relate to menstrual disturbances.

Key terms circadian rhythm; heavy lifting; long work hours; menstrual cycle variation; night shift work; night work; prolonged standing; rotating night shift work; shift work.

The menstrual cycle, defined by cyclical patterns of circulating reproductive hormones [luteinizing hormone (LH), follicle-stimulating hormone (FSH), estrogen, and progesterone], is regulated by the hypothalamo pituitary - ovarian axis (1). Measured by its length and regularity, the menstrual cycle is considered a marker of general reproductive health (2) and has previously been associated with subfertility (3-7). We hypothesize that shifts in the circadian rhythms, either through sleep disturbances or altered melatonin production, may play a role in regulating the reproductive hormones that control the menstrual cycle. Produced in the pineal gland dur- ing dark hours, melatonin is thought to regulate several physiologic mechanisms $(8,9)$.

Shift work is prevalent in the United States; according to the Bureau of Labor Statistics (10), nearly 15 million workers (comprising approximately $15 \%$ of full-time US workers) work evenings, nights, or rotating shifts. Shift work is even more prevalent among healthcare workers, $24-28 \%$ of whom work evenings, nights, or rotating shifts (11). Long working hours are also commonly reported in the US; approximately $25 \%$ of those who are currently employed work $>40$ hours per week [www.bls.gov/cps/cpsaat19.htm].

\footnotetext{
1 National Institute for Occupational Safety and Health, Cincinnati, OH, USA.

2 Epidemic Intelligence Service, Centers for Disease Control and Prevention, Atlanta, GA, USA.

3 Department of Nutrition, Harvard School of Public Health, Boston, MA, USA.

4 Channing Division of Network Medicine, Dept of Medicine, Brigham and Women's Hospital and Harvard Medical School, Boston, MA, USA

5 Department of Epidemiology, Harvard School of Public Health, Boston, MA, USA.

6 Connors Center for Women's Health and Gender Biology, Brigham and Women's Hospital and Harvard Medical School, Boston, MA, USA.
}

Correspondence to: Christina C Lawson, National Institute for Occupational Safety and Health 1090 Tusculum Ave, MS R-15, Cincinnati, OH 45226, USA. [E-mail: clawson@cdc.gov] 
Most previous studies examining the relationship between shift work and menstrual cycle characteristics support an association between working at night and menstrual function, though many of these studies were limited by their small sample sizes or small proportion of women exposed to shift work (12-21). The largest of these studies included 71077 women from the Nurses' Health Study II (NHS II) and showed dose-dependent associations between the number of months performing rotating shift work in the prior 24-month period and higher risk of irregular cycles, and cycles that were short ( $<21$ days) or long ( $\geq 40$ days) (18). No previous studies have evaluated whether permanent night work is as disruptive to menstrual function as rotating night shift work.

Nursing can involve physically and emotionally demanding work, yet there are few previous studies of physically demanding work and menstrual function $(15,16,22-24)$. In these studies, the study populations, statistical modeling, and results vary to the extent that no clear conclusions can be drawn about what effect, if any, the physically demanding work might have on menstrual function.

We examined the associations between work schedule characteristics and physically demanding work and menstrual cycle length and regularity in the Nurses' Health Study 3 (NHS3).

\section{Methods}

\section{Study population}

The NHS3 is a cohort study of US and Canadian female nurses and nursing students born on or after 1 January 1965. Open recruitment started in 2010 and is ongoing. Female registered nurses (RN), licensed practical/ vocational nurses $(\mathrm{LPN} / \mathrm{LVN})$ and nursing students, ages $18-46$ years, are eligible to participate. The NHS3 is an open cohort, and questionnaires are exclusively webbased; participants are asked to complete questionnaires on a regular schedule dating from their study enrollment. The baseline questionnaire includes an assessment of occupational exposures relevant to nurses, including characteristics of current and prior work schedule and physically demanding work. The first follow-up questionnaire (conducted approximately six months after the baseline questionnaire is completed) includes questions on menstrual cycle characteristics.

To be eligible for this analysis, participants had to have completed the baseline and first follow-up questionnaires, which, at the time of analysis, included 15939 participants. Figure 1 describes eligibility and exclusion criteria. After exclusions, 6309 participants were available for analysis.

\section{Data collection}

The baseline questionnaire collected information about current and prior work schedules. Average hours worked per week in the past year were collected in the following categories: $0,1-20,21-40,41-60$, and $>60$ hours/week. For analysis, we considered $>40$ hours/week to be long work hours. Information on current usual work schedule (over the past year) was collected and included days only, evenings only, nights only, rotating with nights, and rotating without nights (ie, rotating between day and evening shifts). For the survey, "night" was defined as most hours worked falling between 24:00-08:00 hours. We also collected data on how many night shifts were worked per month over the past year: 0, 1-2 nights per month, 3-4 nights per month, 2-3 nights per week, and $\geq 4$ nights per week. Women who worked 5-7 nights per month had to choose the closest category (3-4 nights per month or 2-3 nights per week). To assess the history of night shift work, participants reported the number of years they had worked rotating night shifts (defined as at least three nights per month in addition to days or evenings in the same month) and total number of years they worked non-rotating night shifts.

To collect information on physical demands, we asked how many hours per day, on average over the past month, each participant was on her feet at work (standing or walking): $<1,1-4,5-8$, or $\geq 9$ hours/day. We also asked how many times per day, on average over the past month, she lifted or moved a physical load of $\geq 25$ pounds at work (including repositioning or transferring patients): $0,1-5,6-15$, or $\geq 16$ times/day.

The data on work schedules and hours were collected at baseline regarding the prior year, and physical demands data (also collected at baseline) concerned the prior month. Approximately six months to a year after baseline, data on menstrual cycle characteristics were collected in the follow-up questionnaire. Participants provided the current regularity of their menstrual cycles in the following categories: "very regular (+/- 3 days), regular, usually irregular, or always irregular". For analysis, we compared "regular" (very regular or regular) to "irregular" (usually or always irregular).

Participants also reported their current usual menstrual cycle length, defined as the interval from the first day of the period to the first day of the next period. Questionnaire choices included $<21,21-25,26-31,32-39$, and 40-50 days, and " $>50$ days or too irregular to estimate." For analysis, we defined our reference group as 26-31 days, very short cycles as $<21$ days, moderately short cycles as 21-25 days, and long cycles as 32-50 days. Because 96\% of the 316 women who reported that their cycles were " $>50$ days or too irregular to estimate" also reported "usually or always" having irregular cycles, we excluded these 316 women from the analysis of long cycles. 

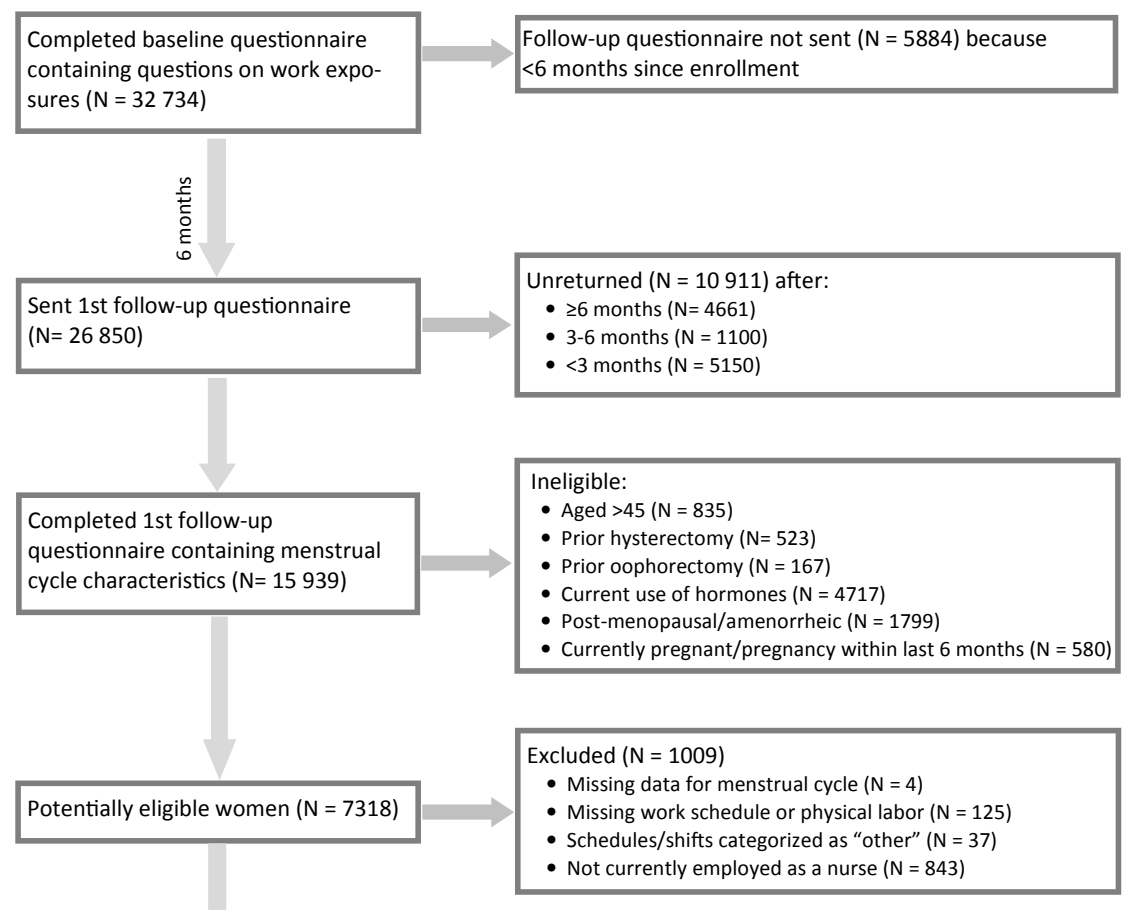

Figure 1. Flow chart of data collection and eligibility, Nurses' Health Study 3

Included women ( $=6309)$

Covariates collected on the questionnaires included age, race/ethnicity, body mass index (BMI), parity, age at menarche, recreational physical activity, smoking status, and caffeine and alcohol consumption (see Table 1 for category definitions).

\section{Statistical analysis}

We used SAS statistical software version 9 (SAS Institute, Cary NC, USA) to conduct all analyses. We calculated age-adjusted means and prevalence of selected characteristics. We used log binomial regression analysis to estimate prevalence ratios (PR) of menstrual cycle characteristics in relation to occupational factors. We created separate models for very short $(<21$ days), moderately short ( $21-<25$ days), or long (32-50 days) cycle length and cycle irregularity. Because the log binomial models did not converge for some of the analyses of very short cycles (due to a small number of cases in some exposure categories), we used logistic regression to estimate prevalence odds ratios (OR) for all analyses of menstrual cycle length. The potential covariates were chosen a priori, based on factors related to menstrual function in previous studies $(5,18,26)$. Covariates that changed the estimate by $\geq 10 \%$ for the occupational variables were retained in the final multivariable model; to maintain consistency across models for the same outcome, if a covariate changed an exposure estimate for one exposure (such as, heavy lifting), we retained it in models for all other work exposures (such as, hours worked) for that menstrual outcome. In practice, the additional covariates had minimal if any difference in the other models. Age, smoking, body mass index (BMI), physical activity, parity, age at menarche, and race/ethnicity were retained as covariates. Of the participants, $<1 \%$ were missing BMI, race/ethnicity, and smoking, and $1.9 \%$ were missing physical activity data (table 1). For covariates with missing data, a missing indicator was created. To calculate a dose-response trend for occupational variables, the midpoint of each reporting category was used to create a continuous variable. To separate the effects of current work schedule and number of years of previous shiftwork, we adjusted the analyses of years of shift work for current schedule.

The Institutional Review Boards of the Brigham and Women's Hospital and the National Institute for Occupational Safety and Health approved the study. Completion of the web-based questionnaires implied informed consent.

\section{Results}

The 6309 nurses in our study ranged in age from 21-45 years at the time of the baseline questionnaire [mean 35.2 , standard deviation (SD) 6.1 years]. With regard to current work schedule, most participants worked the day 
Table 1. Age-standardized characteristics of 6309 participants in the Nurses' Health Study 3 (2010-2012), by current work schedule. [MET=metabolic equivalent of task; SD=standard deviation].

\begin{tabular}{|c|c|c|c|c|c|c|c|c|c|c|c|c|c|}
\hline \multirow[t]{3}{*}{ 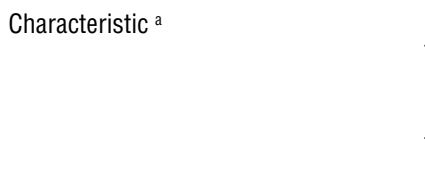 } & \multicolumn{12}{|c|}{ Current work schedule } & \multirow{3}{*}{$\begin{array}{c}\text { Missing } \\
\text { charac- } \\
\text { teristic } \\
\%\end{array}$} \\
\hline & \multicolumn{3}{|c|}{$\begin{array}{l}\text { Days only } \\
(\mathrm{N}=3891)\end{array}$} & \multicolumn{3}{|c|}{$\begin{array}{l}\text { Evenings only or } \\
\text { rotating shifts with no } \\
\text { nights }(\mathrm{N}=610)\end{array}$} & \multicolumn{3}{|c|}{$\begin{array}{l}\text { Nights only } \\
(\mathrm{N}=957)\end{array}$} & \multicolumn{3}{|c|}{$\begin{array}{l}\text { Rotating shifts } \\
\text { with nights } \\
(\mathrm{N}=851)\end{array}$} & \\
\hline & Mean & SD & $\%$ & Mean & SD & $\%$ & Mean & SD & $\%$ & Mean & SD & $\%$ & \\
\hline $\begin{array}{l}\text { Age group (years) } \\
<26 \\
26-30 \\
31-35 \\
36-40 \\
41-45\end{array}$ & & & $\begin{array}{r}3 \\
15 \\
22 \\
27 \\
32\end{array}$ & & & $\begin{array}{r}9 \\
24 \\
25 \\
24 \\
18\end{array}$ & & & $\begin{array}{l}10 \\
26 \\
24 \\
20 \\
20\end{array}$ & & & $\begin{array}{l}12 \\
30 \\
21 \\
21 \\
16\end{array}$ & 0 \\
\hline Age at menarche & 12.4 & 1.4 & & 12.4 & 1.4 & & 12.4 & 1.4 & & 12.4 & 1.6 & & 0 \\
\hline $\begin{array}{l}\text { Age at time of baseline questionnaire } \\
\text { Body mass index }\left(\mathrm{kg} / \mathrm{m}^{2}\right)\end{array}$ & 36.7 & 5.7 & & 34.0 & 6.1 & & 33.7 & 6.2 & & 33.0 & 6.3 & & $\begin{array}{r}0 \\
0.3\end{array}$ \\
\hline$<18.5$ & & & 2 & & & 2 & & & 1 & & & 1 & \\
\hline $18.5-24.9$ & & & 49 & & & 49 & & & 44 & & & 43 & \\
\hline $25.0-29.9$ & & & 25 & & & 24 & & & 23 & & & 26 & \\
\hline $30.0-34.9$ & & & 12 & & & 16 & & & 15 & & & 15 & \\
\hline$\geq 35.0$ & & & 12 & & & 9 & & & 18 & & & 15 & \\
\hline Race/ethnicity & & & & & & & & & & & & & 0.8 \\
\hline African-American & & & 3 & & & 2 & & & 4 & & & 5 & \\
\hline Latina & & & 4 & & & 3 & & & 6 & & & 4 & \\
\hline Asian & & & 3 & & & 3 & & & 4 & & & 3 & \\
\hline Caucasian & & & 89 & & & 92 & & & 86 & & & 88 & \\
\hline Other & & & 1 & & & 0 & & & 0 & & & 1 & \\
\hline Parity & & & & & & & & & & & & & 0 \\
\hline Nulliparous & & & 40 & & & 42 & & & 44 & & & 47 & \\
\hline 1 & & & 19 & & & 16 & & & 12 & & & 12 & \\
\hline $2-3$ & & & 38 & & & 39 & & & 40 & & & 37 & \\
\hline$\geq 4$ & & & 3 & & & 3 & & & 5 & & & 5 & \\
\hline Cigarette smoking & & & & & & & & & & & & & 0.1 \\
\hline Never smoked & & & 76 & & & 71 & & & 73 & & & 72 & \\
\hline Past smoker & & & 19 & & & 23 & & & 19 & & & 22 & \\
\hline Current smoker & & & 5 & & & 6 & & & 8 & & & 6 & \\
\hline Alcohol intake (drinks/day) & & & & & & & & & & & & & 12.8 \\
\hline None & & & 27 & & & 29 & & & 33 & & & 25 & \\
\hline$<1$ & & & 55 & & & 56 & & & 55 & & & 57 & \\
\hline 1 & & & 7 & & & 6 & & & 4 & & & 6 & \\
\hline $2-3$ & & & 9 & & & 8 & & & 7 & & & 9 & \\
\hline$\geq 4$ & & & 1 & & & 2 & & & 1 & & & 2 & \\
\hline $\begin{array}{l}\text { Coffee intake (number of } 10 \text { oz cups/ } \\
\text { week) }\end{array}$ & 8.5 & 11.1 & & 9.2 & 10.9 & & 8.9 & 13.0 & & 8.7 & 11.3 & & 12.4 \\
\hline MET'(per week) & & & & & & & & & & & & & 1.9 \\
\hline $0-2.9$ & & & 14 & & & 15 & & & 18 & & & 13 & \\
\hline $3.0-8.9$ & & & 17 & & & 17 & & & 17 & & & 15 & \\
\hline $9.0-17.9$ & & & 17 & & & 18 & & & 16 & & & 18 & \\
\hline $18.0-26.9$ & & & 13 & & & 12 & & & 10 & & & 15 & \\
\hline $27.0-41.9$ & & & 15 & & & 13 & & & 14 & & & 15 & \\
\hline$\geq 42.0$ & & & 25 & & & 25 & & & 24 & & & 24 & \\
\hline Lifting $\geq 25$ Ibs per day (times/day) & & & & & & & & & & & & & 0 \\
\hline No lifting & & & 43 & & & 20 & & & 12 & & & 19 & \\
\hline $1-5$ & & & 38 & & & 47 & & & 43 & & & 43 & \\
\hline $6-15$ & & & 15 & & & 25 & & & 35 & & & 30 & \\
\hline$\geq 16$ & & & 4 & & & 8 & & & 10 & & & 8 & \\
\hline On feet at work (hour/day) & & & & & & & & & & & & & 0 \\
\hline$<1$ & & & 10 & & & 4 & & & 2 & & & 2 & \\
\hline $1-4$ & & & 37 & & & 19 & & & 9 & & & 12 & \\
\hline $5-8$ & & & 29 & & & 48 & & & 39 & & & 37 & \\
\hline$\geq 9$ & & & 24 & & & 29 & & & 49 & & & 48 & \\
\hline Worked rotating night shift (years) & & & & & & & & & & & & & 0 \\
\hline None & & & 61 & & & 60 & & & 68 & & & 7 & \\
\hline $1-2$ & & & 19 & & & 21 & & & 16 & & & 39 & \\
\hline $3-5$ & & & 13 & & & 11 & & & 8 & & & 25 & \\
\hline$\geq 6$ & & & 7 & & & 7 & & & 8 & & & 29 & \\
\hline Worked non-rotating night shift (years) & & & & & & & & & & & & & 0 \\
\hline None & & & 49 & & & 54 & & & 6 & & & 45 & \\
\hline $1-2$ & & & 25 & & & 23 & & & 29 & & & 24 & \\
\hline $3-5$ & & & 15 & & & 14 & & & 25 & & & 17 & \\
\hline$\geq 6$ & & & 11 & & & 9 & & & 39 & & & 15 & \\
\hline
\end{tabular}


shift (61.7\%), with the rest working evenings or rotating shifts without nights $(9.7 \%)$, nights only $(15.2 \%)$, or rotating shifts with $\geq 3$ nights per month (13.5\%). Nurses who worked night shifts or rotating night shifts were on average - younger, more likely to be overweight or obese, nulliparous, and current or former smokers than nurses working other schedules (table 1). Physically demanding work also varied by current work schedule; nurses working day shifts were half as likely to have heavy-lifting duties and were also less likely to engage in prolonged standing than nurses working other shifts.

\section{Irregular cycles}

Of 6309 participants, 1196 nurses reported having irregular menstrual cycles (19.0\%). In adjusted models (table 2), working $>40$ hours per week in the past year was associated with a modestly higher prevalence of irregular cycles [PR 1.16, 95\% confidence interval (95\% CI) 1.04-1.29] compared to working 21-40 hours/week ( $\mathrm{P}$ for trend $=0.01)$. Prevalence of irregular cycles was higher among nurses who worked nights only (PR 1.32, 95\% CI 1.15-1.51) or rotating shifts with nights (PR $1.27,95 \%$ CI 1.10-1.47) compared to nurses working days only, and the prevalence increased with the number of nights worked per month ( $P$ for trend $<0.0001$ ). Though the associations of years of rotating night shifts were attenuated after adjustment for covariates, including current shift schedule, there was still a suggestion of an association between irregular cycles and years of rotating night shift $(\mathrm{P}$ for trend $=0.06)$. An association with years of night shift not involving rotation was eliminated in adjusted models, however, primarily due to adjustments for BMI and current work shift schedule. We also analyzed years of rotating and non-rotating night shift in separate models stratified by whether the current work schedule was days or non-days, and we saw no difference (data not shown).

Physically demanding work was also associated with irregular cycles (table 2). A greater amount of heavy lifting was associated with higher prevalence of irregular cycles in the fully adjusted model (PR for lifting $\geq 16$ times/day compared to no lifting: 1.34 , 95\% CI $1.07-$ 1.68). Although prolonged standing was associated with higher prevalence of irregular cycles in the age-adjusted model, further adjustment - particularly for amount of heavy lifting - attenuated the association of prolonged standing with menstrual irregularity.

\section{Cycle length}

Respectively, 92 (1.5\%), 935 (15.6\%), and 789 (13.2\%) participants reported menstrual cycle lengths of $<21$ (very short), 21-25 (moderately short), and 32-50 (long) days. A majority [4177 (69.7\%)] reported cycles lasting 26-31 days (reference category). In age-adjusted models, long working hours were associated with very short cycles, rotating night work was associated with very short and long cycles, and prolonged standing and high amount of heavy lifting were associated with very short and moderately short cycles (table 3 ).

After further adjustment for potential confounders (table 4), long working hours were associated with very short cycles (OR 1.93, 95\% CI 1.24-3.01 for $\geq 41$ versus 21-40 hours/week; P for trend $=0.002$ ). Rotating night shift work was associated with very short cycles (OR $1.75,95 \%$ CI 0.98-3.12) and long cycles (OR 1.28, 95\% CI 1.03-1.61); however, working nights without rotation was not associated with cycle length. Moreover, neither current amount of nor years of night work showed any clear trend with regard to extremes of cycle length, though confidence intervals were wide.

Nurses who reported frequent heavy lifting at work were more likely to experience very short or moderately short cycles ( $\mathrm{P}$ for trend $=0.02$ for each endpoint) (table 4). As was the case for cycle irregularity, the dose-response association of time spent standing with short-cycle length (table 3) was somewhat explained in fully adjusted models (table 4) by its correlation with heavy lifting (correlation coefficient $=0.6$ ).

\section{Discussion}

The results of our study suggest an association between working at night and menstrual function, including higher prevalence of cycle irregularity, very short cycles, and long cycles. In addition, long working hours were associated with a modestly higher prevalence of irregularity, and a near doubling of prevalence of very short cycles. There were trends towards higher prevalence of irregular cycles and shorter cycle lengths among participants with higher amounts of heavy lifting. The associations of prolonged standing with menstrual function observed in age-adjusted models appeared to be somewhat explained in fully-adjusted models by confounding by heavy lifting; as would be expected, there was a correlation between lifting and standing among nurses.

Most previous studies of work schedule and menstrual function support an effect of night shift work on the menstrual cycle $(12-19,21)$, though sample sizes were low for some $(13,14,15,17,19)$, limiting their ability to adjust for confounding factors. Compared to other studies of shift work and menstrual cycle among nurses $(13,14,15,18,19)$, this is the only study to include nursing students and Canadian nurses, and it has a higher percentage of non-hospital nurses and AfricanAmerican nurses.

Our previous study of 71077 participants from the 
Table 2. Risk of irregular menstrual pattern with current work schedule, history of shift work, and physically demanding work among 6309 participants of the Nurses' Health Study 3 (2010-2012). a [PR=prevalence ratio; 95\% Cl=95\% confidence interval]

\begin{tabular}{|c|c|c|c|c|c|c|c|}
\hline \multirow[t]{2}{*}{ Occupational risk factor } & \multirow{2}{*}{$\begin{array}{l}\text { Number with } \\
\text { irregular cycles }\end{array}$} & \multicolumn{2}{|c|}{ Age-adjusted ${ }^{\mathrm{b}}$} & \multirow[t]{2}{*}{ P-value ${ }^{d}$} & \multicolumn{2}{|c|}{ Full model ${ }^{\mathrm{c}}$} & \multirow[t]{2}{*}{$P$-value ${ }^{d}$} \\
\hline & & PR & $95 \% \mathrm{Cl}$ & & PR & $95 \% \mathrm{Cl}$ & \\
\hline $\begin{array}{l}\text { Average working time in } \\
\text { past year (hours/week) }\end{array}$ & & & & 0.0002 & & & 0.01 \\
\hline $1-20$ & 83 & 0.88 & $0.72-1.09$ & & 0.94 & $0.76-1.16$ & \\
\hline 21-40 (reference) & 718 & 1.00 & & & 1.00 & & \\
\hline$\geq 41$ & 395 & 1.21 & $1.08-1.35$ & & 1.16 & $1.04-1.29$ & \\
\hline Work schedule (past year) & & & & & & & \\
\hline Days only (reference) & 654 & 1.00 & & & 1.00 & .. & \\
\hline $\begin{array}{l}\text { Evenings only or rotating } \\
\text { without nights }\end{array}$ & 119 & 1.12 & $0.94-1.34$ & & 1.14 & $0.96-1.36$ & \\
\hline Nights only & 229 & 1.36 & $1.19-1.56$ & & 1.32 & $1.15-1.51$ & \\
\hline Rotating with nights & 194 & 1.30 & $1.12-1.50$ & & 1.27 & $1.10-1.47$ & \\
\hline Nights worked (past month) & & & & $<0.0001$ & & & $<0.0001$ \\
\hline 0 (reference) & 765 & 1.00 & & & 1.00 & .. & \\
\hline 1-4 nights per month & 147 & 1.15 & $0.98-1.35$ & & 1.14 & $0.97-1.33$ & \\
\hline$\geq 2$ nights per week & 284 & 1.34 & $1.18-1.51$ & & 1.29 & $1.14-1.46$ & \\
\hline $\begin{array}{l}\text { Rotating night shift (years } \\
\text { worked) e }\end{array}$ & & & & 0.01 & & & 0.06 \\
\hline 0 (reference) & 608 & 1.00 & & & 1.00 & .. & \\
\hline $1-2$ & 287 & 1.11 & $0.97-1.25$ & & 1.09 & $0.96-1.24$ & \\
\hline $3-5$ & 175 & 1.17 & $1.00-1.36$ & & 1.17 & $1.00-1.35$ & \\
\hline$\geq 6$ & 126 & 1.23 & $1.03-1.46$ & & 1.17 & $0.98-1.40$ & \\
\hline $\begin{array}{l}\text { Night work not involving } \\
\text { rotation (years worked) }\end{array}$ & & & & 0.004 & & & 0.5 \\
\hline 0 (reference) & 465 & 1.00 & .. & & 1.00 & .. & \\
\hline $1-2$ & 331 & 1.11 & $0.98-1.26$ & & 1.06 & $0.93-1.21$ & \\
\hline $3-5$ & 205 & 1.12 & $0.97-1.30$ & & 1.01 & $0.87-1.17$ & \\
\hline$\geq 6$ & 195 & 1.25 & $1.07-1.46$ & & 1.07 & $0.91-1.26$ & \\
\hline $\begin{array}{l}\text { Heavy lifting at work (times/ } \\
\text { day) e, f,g }\end{array}$ & & & & $<0.0001$ & & & 0.08 \\
\hline 0 (reference) & 324 & 1.00 & & & 1.00 & .. & \\
\hline $1-5$ & 502 & 1.27 & $1.12-1.45$ & & 1.17 & $1.01-1.35$ & \\
\hline $6-15$ & 281 & 1.33 & $1.15-1.53$ & & 1.17 & $0.98-1.39$ & \\
\hline$\geq 16$ & 89 & 1.58 & $1.28-1.94$ & & 1.34 & $1.07-1.68$ & \\
\hline $\begin{array}{l}\text { On feet at work (hours/ } \\
\text { day) e, f }\end{array}$ & & & & 0.001 & & & 0.3 \\
\hline$<1$ (reference) & 64 & 1.00 & & & 1.00 & & \\
\hline $1-4$ & 303 & 1.19 & $0.93-1.53$ & & 1.11 & $0.86-1.43$ & \\
\hline $5-8$ & 422 & 1.37 & $1.07-1.74$ & & 1.14 & $0.87-1.48$ & \\
\hline$\geq 9$ & 407 & 1.40 & $1.09-1.78$ & & 1.11 & $0.84-1.46$ & \\
\hline
\end{tabular}

a Irregular pattern defined as $>3$ days variability among cycles. $\mathrm{N}=1196(19.0 \%)$.

${ }^{\mathrm{b}}$ These models test associations for each work factor separately, adjusting for age.

' Full models test associations for each work factor separately, adjusting for age, BMI, physical activity, smoking, race, parity, and age at menarche.

${ }^{\mathrm{d}}$ To test for trend, the work factor was modeled continuously, with the adjustment factors modeled categorically.

${ }^{e}$ These models also adjust for frequency of current night work in the full models.

${ }^{\dagger}$ Frequency of heavy lifting and hours spent on feet and are adjusted for each other in the full models.

${ }^{g}$ Lifting refers to lifting or moving a physical load of $\geq 25$ pounds, including repositioning or transferring patients, measured as times per day.

NHS II, the largest study to date, showed that the number of months spent working rotating night shift over the previous two years was modestly related to irregularity, as well as very short ( $<21$ days) or very long ( $\geq 40$ days) cycle lengths (18). It was unclear in that study, however, if the trends reflected a cumulative dose-response relationship over time, or if women reporting more months of shift work were more likely to have been current shift workers at the time they completed the questionnaire (18).

Our current study shows a suggested trend towards higher prevalence of cycle irregularity with increasing years of rotating night work. A separate analysis of years of rotating night work stratified by current schedule (day versus other) did not show any differences. Thus, our data suggest that there may be a dose-response relationship between number of years working rotating night shift and current menstrual cycle function. Furthermore, it appears that the association does not entirely dissipate when rotating night shift work ceases, at least in the short term. Our measure of current shift work, which includes night work cessation if the participant reported previous night shift but was on a current day shift, was only captured for the prior 12 months. It is possible that effects of night work on menstrual function take $>12$ months to diminish. In addition, if a participant did cease night work, we do not know when she ceased. Future analyses of NHS3 data 
Table 3. Age-adjusted associations of current work schedule, history of shift work, and physically demanding work with short and long menstrual cycle length among 5993 a participants of the Nurses' Health Study 3 (2010-2012). ${ }^{\text {b }}$ OR=odds ratio; 95\% Cl=95\% confidence interval]

\begin{tabular}{|c|c|c|c|c|c|c|c|c|c|}
\hline & \multicolumn{3}{|c|}{$\begin{array}{l}\text { Very short: }<21 \text { days } \\
\quad N=92(1.5 \%) c, d\end{array}$} & \multicolumn{3}{|c|}{$\begin{array}{l}\text { Moderately short: } 21-25 \text { days } \\
\qquad \mathrm{N}=935(15.6 \%)^{c}\end{array}$} & \multicolumn{3}{|c|}{$\begin{array}{l}\text { Long: } 32-50 \text { days }^{\text {a }} \\
\mathrm{N}=789(13.2 \%)^{\mathrm{c}}\end{array}$} \\
\hline & $\mathrm{OR}$ & $95 \% \mathrm{Cl}$ & P-value ${ }^{e}$ & $\mathrm{OR}$ & $95 \% \mathrm{Cl}$ & P-value ${ }^{e}$ & $\mathrm{OR}$ & $95 \% \mathrm{Cl}$ & P-value ${ }^{e}$ \\
\hline $\begin{array}{l}\text { Average working time in } \\
\text { past year (hours/week) }\end{array}$ & & & 0.002 & & & 0.3 & & & 0.8 \\
\hline $1-20$ & 0.95 & $0.40-2.25$ & & 1.18 & $0.92-1.52$ & & 1.04 & $0.79-1.38$ & \\
\hline 21-40 (reference) & 1.00 & .. & & 1.00 & .. & & 1.00 & .. & \\
\hline$\geq 41$ & 1.91 & $1.24-2.94$ & & 1.18 & $1.01-1.38$ & & 0.99 & $0.83-1.18$ & \\
\hline Work schedule (past year) & & & & & & & & & \\
\hline Days only (reference) & 1.00 & .. & & 1.00 & .. & & 1.00 & .. & \\
\hline $\begin{array}{l}\text { Evenings only or rotating } \\
\text { without nights }\end{array}$ & 1.06 & $0.50-2.26$ & & 1.01 & $0.79-1.31$ & & 0.98 & $0.75-1.29$ & \\
\hline Nights only & 1.01 & $0.52-1.95$ & & 1.11 & $0.90-1.37$ & & 1.16 & $0.94-1.45$ & \\
\hline Rotating with nights & 1.81 & $1.02-3.22$ & & 1.12 & $0.89-1.40$ & & 1.27 & $1.01-1.58$ & \\
\hline Nights worked (past month) & & & 0.6 & & & 0.2 & & & 0.1 \\
\hline 0 (reference) & 1.00 & .. & & 1.00 & .. & & 1.00 & .. & \\
\hline 1-4 nights per month & 1.02 & $0.50-2.06$ & & 1.12 & $0.89-1.41$ & & 1.04 & $0.81-1.33$ & \\
\hline$\geq 2$ nights per week & 1.25 & $0.72-2.15$ & & 1.11 & $0.92-1.35$ & & 1.21 & $1.00-1.47$ & \\
\hline $\begin{array}{l}\text { Rotating night shift (years } \\
\text { worked) }\end{array}$ & & & 0.7 & & & 0.98 & & & 0.05 \\
\hline 0 (reference) & 1.00 & .. & & 1.00 & .. & & 1.00 & .. & \\
\hline $1-2$ & 1.24 & $0.74-2.08$ & & 1.03 & $0.86-1.23$ & & 0.97 & $0.80-1.18$ & \\
\hline $3-5$ & 1.11 & $0.60-2.05$ & & 0.96 & $0.78-1.20$ & & 1.01 & $0.80-1.28$ & \\
\hline$\geq 6$ & 1.19 & $0.62-2.30$ & & 1.05 & $0.82-1.33$ & & 1.36 & $1.04-1.79$ & \\
\hline $\begin{array}{l}\text { Night work not involving } \\
\text { rotation (years worked) }\end{array}$ & & & 0.6 & & & 0.74 & & & 0.6 \\
\hline 0 (reference) & 1.00 & .. & & 1.00 & .. & & 1.00 & .. & \\
\hline $1-2$ & 1.17 & $0.70-1.95$ & & 1.13 & $0.94-1.35$ & & 1.26 & $1.04-1.52$ & \\
\hline $3-5$ & 0.70 & $0.36-1.39$ & & 1.19 & $0.97-1.46$ & & 1.29 & $1.03-1.61$ & \\
\hline$\geq 6$ & 1.06 & $0.59-1.89$ & & 0.98 & $0.79-1.21$ & & 1.16 & $0.90-1.49$ & \\
\hline $\begin{array}{l}\text { Heavy lifting at work (times/ } \\
\text { day) }{ }^{f}\end{array}$ & & & $<0.0001$ & & & 0.0007 & & & 0.5 \\
\hline 0 (reference) & 1.00 & .. & & 1.00 & .. & & 1.00 & .. & \\
\hline $1-5$ & 1.14 & $0.66-1.96$ & & 1.28 & $1.08-1.52$ & & 1.04 & $0.87-1.25$ & \\
\hline $6-15$ & 2.57 & $1.49-4.42$ & & 1.46 & $1.19-1.78$ & & 1.05 & $0.84-1.30$ & \\
\hline$\geq 16$ & 3.14 & $1.43-6.89$ & & 1.42 & $1.02-1.98$ & & 1.14 & $0.81-1.61$ & \\
\hline On feet at work (hours/day) & & & 0.0003 & & & 0.01 & & & 0.2 \\
\hline$<4$ (reference) & 1.00 & .. & & 1.00 & .. & & 1.00 & .. & \\
\hline $5-8$ & 1.67 & $0.96-2.88$ & & 0.93 & $0.78-1.10$ & & 1.12 & $0.93-1.36$ & \\
\hline$\geq 9$ & 2.57 & $1.51-4.37$ & & 1.27 & $1.06-1.51$ & & 1.13 & $0.93-1.37$ & \\
\hline
\end{tabular}

a Does not include women who reported their cycles were $51+$ days long and that they usually or always had irregular menstrual patterns ( $\mathrm{N}=316$ ).

b Compared to cycle length of $26-31$ days $(\mathrm{N}=4177)$.

c Reflects the percentage of participants with the outcome of interest compared to the referent group (26-31 days).

${ }^{d}$ Age was modeled continuously for cycles $<21$ days due to the few number of cases.

e To test for trend, the work factor was modeled continuously, with the adjustment factors modeled categorically.

${ }^{\dagger}$ Lifting refers to lifting or moving a physical load of 25 pounds or more, including repositioning or transferring patients, measured as times per day.

may be able to better assess the effects of night work cessation on menstrual function.

In our study, working nights with rotation and without rotation have similar associations with menstrual regularity, though working nights without rotation was not associated with cycle length. Our study also shows a trend towards increasing prevalence of irregularity with higher number of nights worked per month, though the association between number of nights per month and cycle length was less clear, possibly due to lower power among the outcome categories.

More hours of work per week were associated with higher prevalence of irregularity and very short cycle length. Few previous studies have examined working hours and menstrual function. One study reported that working hours among Taiwanese nurses was not related to cycle irregularity (13). Another study reported higher risks of irregularity, amenorrhea, and long cycles with variability in weekly working hours (16), though it did not report the effects of long hours specifically.

Our results showing higher prevalence of irregular cycles and short cycle length with heavy lifting should be interpreted cautiously, because there are few studies of physically demanding work and menstrual function, and the causal relationships between standing, lifting, and other workplace characteristics have not been clearly delineated. A French study of poultry slaughterhouse workers reported that "regularly handling weights" 
Table 4. Adjusted models a: Association between work schedule, history of shift work, and physically demanding work with short and long menstrual cycle length among 5993 ' participants of the Nurses' Health Study 3 (2010-2012). [OR=odds ratio; 95\% Cl=95\% confidence interval]

\begin{tabular}{|c|c|c|c|c|c|c|c|c|c|}
\hline & \multicolumn{3}{|c|}{$\begin{array}{l}\text { Very short: }<21 \text { days } \\
N=92(1.5 \%)^{c, d}\end{array}$} & \multicolumn{3}{|c|}{$\begin{array}{c}\text { Moderately short: } 21-25 \text { days } \\
N=935(15.6 \%)^{\mathrm{c}}\end{array}$} & \multicolumn{3}{|c|}{$\begin{array}{l}\text { Long: } 32-50 \text { days }^{b} \\
N=789(13.2 \%)^{c}\end{array}$} \\
\hline & $\mathrm{OR}$ & $95 \% \mathrm{Cl}$ & P-value ${ }^{e}$ & $\mathrm{OR}$ & $95 \% \mathrm{Cl}$ & P-value e & $\mathrm{OR}$ & $95 \% \mathrm{Cl}$ & $\mathrm{P}$-value ${ }^{\mathrm{e}}$ \\
\hline Hours worked per week & & & 0.002 & & & 0.4 & & & 0.4 \\
\hline $1-20$ & 0.98 & $0.41-2.34$ & & 1.19 & $0.92-1.54$ & & 1.06 & $0.80-1.42$ & \\
\hline 21-40 (reference) & 1.00 & & & 1.00 & .. & & 1.00 & & \\
\hline$\geq 41$ & 1.93 & $1.24-3.01$ & & 1.18 & $1.00-1.38$ & & 0.94 & $0.79-1.13$ & \\
\hline Work schedule (past year) & & & & & & & & & \\
\hline Days only (reference) & 1.00 & & & 1.00 & .. & & 1.00 & & \\
\hline $\begin{array}{l}\text { Evenings only or rotating } \\
\text { without nights }\end{array}$ & 0.96 & $0.45-2.05$ & & 0.97 & $0.76-1.26$ & & 1.01 & $0.77-1.32$ & \\
\hline Nights only & 0.96 & $0.50-1.88$ & & 1.06 & $0.86-1.32$ & & 1.14 & $0.92-1.42$ & \\
\hline Rotating with nights & 1.75 & $0.98-3.12$ & & 1.08 & $0.86-1.36$ & & 1.28 & $1.03-1.61$ & \\
\hline Nights worked (past month) & & & 0.6 & & & 0.4 & & & 0.2 \\
\hline 0 (reference) & 1.00 & .. & & 1.00 & . & & 1.00 & & \\
\hline $1-4$ nights per month & 0.99 & $0.48-2.01$ & & 1.09 & $0.87-1.38$ & & 1.06 & $0.83-1.35$ & \\
\hline$\geq 2$ nights per week & 1.25 & $0.72-2.17$ & & 1.08 & $0.89-1.31$ & & 1.18 & $0.97-1.44$ & \\
\hline $\begin{array}{l}\text { Rotating night shift (years } \\
\text { worked) }\end{array}$ & & & 0.7 & & & 0.9 & & & 0.1 \\
\hline 0 (reference) & 1.00 & & & 1.00 & .. & & 1.00 & & \\
\hline $1-2$ & 1.27 & $0.75-2.15$ & & 1.02 & $0.85-1.23$ & & 0.97 & $0.80-1.18$ & \\
\hline $3-5$ & 1.17 & $0.63-2.17$ & & 0.96 & $0.77-1.20$ & & 1.01 & $0.79-1.28$ & \\
\hline$\geq 6$ & 1.23 & $0.63-2.43$ & & 1.05 & $0.82-1.34$ & & 1.28 & $0.96-1.69$ & \\
\hline $\begin{array}{l}\text { Night work not involving } \\
\text { rotation (years worked) }\end{array}$ & & & 0.6 & & & 0.8 & & & 0.6 \\
\hline 0 (reference) & 1.00 & .. & & 1.00 & .. & & 1.00 & .. & \\
\hline $1-2$ & 1.12 & $0.67-1.89$ & & 1.13 & $0.94-1.36$ & & 1.26 & $1.04-1.52$ & \\
\hline $3-5$ & 0.68 & $0.34-1.36$ & & 1.21 & $0.99-1.49$ & & 1.19 & $0.95-1.50$ & \\
\hline$\geq 6$ & 1.04 & $0.56-1.91$ & & 1.00 & $0.79-1.25$ & & 1.04 & $0.80-1.35$ & \\
\hline $\begin{array}{l}\text { Heavy lifting at work (times/ } \\
\text { day) }{ }^{f, g, h}\end{array}$ & & & 0.02 & & & 0.02 & & & 0.6 \\
\hline None (reference) & 1.00 & & & 1.00 & & & 1.00 & & \\
\hline $1-5$ & 0.90 & $0.49-1.68$ & & 1.34 & $1.10-1.62$ & & 0.95 & $0.78-1.17$ & \\
\hline $6-15$ & 1.74 & $0.87-3.45$ & & 1.46 & $1.14-1.86$ & & 0.92 & $0.71-1.19$ & \\
\hline$\geq 16$ & 2.20 & $0.88-5.46$ & & 1.41 & $0.97-2.03$ & & 0.96 & $0.66-1.40$ & \\
\hline On feet at work (hours/day) f, g & & & 0.06 & & & 0.6 & & & 0.3 \\
\hline$<4$ (reference) & 1.00 & .. & & 1.00 & .. & & 1.00 & .. & \\
\hline $5-8$ & 1.52 & $0.81-2.86$ & & 0.78 & $0.64-0.95$ & & 1.12 & $0.90-1.38$ & \\
\hline$\geq 9$ & 1.83 & $0.92-3.64$ & & 1.00 & $0.81-1.25$ & & 1.15 & $0.90-1.46$ & \\
\hline
\end{tabular}

${ }^{a}$ Adjusted for exercise level, BMI, current smoking level, age at interview, age at menarche, race, and parity.

${ }^{b}$ Excludes women who reported their cycles were 51 + days long and that they usually or always had irregular menstrual patterns $(\mathrm{N}=316)$.

c Reflects the percentage of participants with the outcome of interest compared to the referent group (26-31 days; $\mathrm{N}=4177$ ).

d Physical activity, BMI, and age are modeled continuously for models of cycle lengths $<21$ days due to the few number of cases.

${ }^{\mathrm{e}}$ To test for trend, the work factor was modeled continuously, with the adjustment factors modeled categorically.

$f$ These models also adjust for frequency of current night work in the full models.

${ }^{9}$ Hours spent on feet and amount of heavy lifting are adjusted for each other in these full models.

${ }^{n}$ Lifting refers to lifting or moving a physical load of 25 pounds or more, including repositioning or transferring patients, measured as times per day.

resulted in higher risks of irregular cycles, long cycles, and amenorrhea (16); no effects on menstrual function were noted with prolonged standing. A study of tertiary care nurses showed a higher risk of long cycles among nurses with strenuous job activity (15).

Working during nighttime hours may disturb the reproductive hormones that control the menstrual cycle, possibly through sleep disturbances or altered melatonin production. The mechanisms by which long working hours are related to adverse reproductive outcomes is unclear but, perhaps, are related to stress, mental or physical fatigue, or chronic sleep deprivation, disturbing circadian rhythms (27). Physically demanding work could influence menstrual function via altered circulating androgens (28), or it is possible psychosocial stress or fatigue resulting from repetitive physical demands may result in biochemical responses (eg, increased secretion of cortisol and $\alpha$-amylase) which may reduce fertility (29).

Our study is limited by a lack of adequate information on sleep behaviors; it is possible that effective sleep hygiene and education may moderate effects of working nights or rotating night shifts (30). In addition, some of our results might have been affected by excluding women who were taking oral contraceptives for irregular cycles. We were also limited by the cross-sectional and self-reported nature of our data collection; however, 
nurses in the similar NHS I and NHS II were shown to report health data accurately for several medical conditions $(31,32)$. Previous studies that have investigated the accuracy of self-reported menstrual cycle length by comparing initial self-reported "usual" length with prospective diaries, however, Jukic et al (33) and Small et al (34) reported that $21 \%$ of cycle length categories were misclassified. These studies also found that accuracy was better for sexually active women and women with a history of infertility, and that reporting accuracy was lower with irregular cycles and among those with the most extreme lengths. Factors associated with differences in reporting accuracy included parity, BMI, irregular cycles, younger age, single, lower income, and exercise. Misclassification of cycle length is a possibility in the current study, and the direction and magnitude of bias that might arise is difficult to predict. However, it is reassuring that many of the factors that are associated with inaccurate reporting are controlled for in our analyses and that our cohort is comprised of women educated in the medical field. In addition, the fact that we found the expected differences in cycle length with age and BMI suggests that the participants' selfreported data were adequate. Nevertheless, our study is one of the largest studies to examine work schedule, working hours, and physically demanding work with menstrual function. Thus, we were able to assess a more extreme definition of short cycles than other studies and strengthen our results by adjusting for confounding factors such as age, BMI, and recreational physical activity.

In summary, our results indicate a possible role for night work, long working hours, and physically demanding work in menstrual function disturbances, which may have implications for subfertility $(3,5,6)$ and overall health (2). Our study suggests that working rotating nights may have similar effects as working nonrotating nights, and that there may be a dose-response effect with the number of nights worked per month. Questions remain regarding whether the effects from working nights may dissipate once shift work ends. Future research could also assess whether interventions to reduce heavy lifting would improve menstrual function or subfertility.

\section{Acknowledgments}

This work was partially funded by contract number 2002013-M-54978 to the Brigham and Women's Hospital from the Centers for Disease Control and Prevention / National Institute for Occupational Safety and Health and by the Breast Cancer Research Foundation.

We thank Jennifer Hankins and Gary Chase for their efforts establishing the NHS3 cohort and Leslie
MacDonald for her consultation on occupational physical demands.

The findings and conclusions in this report are those of the author(s) and do not necessarily represent the views of the National Institute for Occupational Safety and Health. The authors declare no conflicts of interest.

\section{References}

1. Baker FC, Driver HS. Circadian Rhythms, Sleep, and the Menstrual Cycle. Sleep Med. 2007 Sep;8(6):613-22. http:// dx.doi.org/10.1016/j.sleep.2006.09.011.

2. Harlow SD, Ephross SA. Epidemiology of Menstruation and Its Relevance to Women's Health. Epidemiol Rev. 1995;17(2):265-86.

3. Waller K, Swan SH, Windham GC, Fenster L, Elkin EP, Lasley BL. Use of Urine Biomarkers to Evaluate Menstrual Function in Healthy Premenopausal Women. Am J Epidemiol. 1998;147(11):1071-80. http://dx.doi.org/10.1093/ oxfordjournals.aje.a009401.

4. Jensen TK, Scheike T, Keiding N, Schaumburg I, Grandjean P. Fecundability in Relation to Body Mass and Menstrual Cycle Patterns. Epidemiology. 1999;10(4):422-8. http://dx.doi. org/10.1097/00001648-199907000-00014.

5. Rowland AS, Baird DD, Long S, Wegienka G, Harlow SD, Alavanja $M$, et al. Influence of Medical Conditions and Lifestyle Factors on the Menstrual Cycle. Epidemiology. 2002 Nov;13(6):668-74. http://dx.doi.org/10.1097/00001648200211000-00011.

6. Axmon A, Rylander L, Albin M, Hagmar L. Factors Affecting Time to Pregnancy. Hum Reprod. 2006 May;21(5):1279-84. http://dx.doi.org/10.1093/humrep/dei469.

7. Small CM, Manatunga AK, Klein M, Dominguez CE, Feigelson HS, McChesney R, et al. Menstrual Cycle Variability and the Likelihood of Achieving Pregnancy. Rev Environ Health. 2010 Oct-Dec;25(4):369-78. http://dx.doi. org/10.1515/REVEH.2010.25.4.369.

8. Brzezinski A. Melatonin in Humans. N Engl J Med. 1997;336(3):186-95. http://dx.doi.org/10.1056/ NEJM199701163360306.

9. Cagnacci A. Melatonin in Relation to Physiology in Adult Humans. J Pineal Res. 1996;21(4):200-13. http://dx.doi. org/10.1111/j.1600-079X.1996.tb00287.x.

10. Workers on Flexible and Shift Schedules in 2004 Summary. Bureau of Labor Statistics; 2005 [cited 2010 March 22]. Available from: http://www.bls.gov/news.release/flex.nr0. $\mathrm{htm}$.

11. McMenamin TM. A Time to Work: Recent Trends in Shift Work and Flexible Schedules. Monthly Labor Review. 2007. p. 3-15.

12. Su SB, Lu CW, Kao YY, Guo HR. Effects of 12-Hour Rotating Shifts on Menstrual Cycles of Photoelectronic Workers in Taiwan. Chronobiol Int. 2008;25(2):237-48. http://dx.doi. org/10.1080/07420520802106884. 
13. Chung FF, Yao CC, Wan GH. The Associations between Menstrual Function and Life Style/Working Conditions among Nurses in Taiwan. J Occup Health. 2005 Mar;47(2):149-56. http://dx.doi.org/10.1539/joh.47.149.

14. Labyak S, Lava S, Turek F, Zee P. Effects of Shiftwork on Sleep and Menstrual Function in Nurses. Health Care Women Int. 2002;23(6-7):703-14. http://dx.doi. org/10.1080/07399330290107449.

15. Hatch MC, Figa-Talamanca I, Salerno S. Work Stress and Menstrual Patterns among American and Italian Nurses. Scand J Work Environ Health. 1999;25(2):144-50. http://dx.doi. org/10.5271/sjweh.417.

16. Messing K, Saurel-Cubizolles MJ, Bourgine M, Kaminski M. Menstrual-Cycle Characteristics and Work Conditions of Workers in Poultry Slaughterhouses and Canneries. Scand J Work Environ Health. 1992;18(5):302-9. http://dx.doi. $\operatorname{org} / 10.5271 /$ sjweh. 1572 .

17. Lohstroh PN, Chen J, Ba J, Ryan LM, Xu X, Overstreet JW, et al. Bone Resorption Is Affected by Follicular Length in Female Rotating Shift Workers. Environ Health Perspect. 2003;111(4):618-22. http://dx.doi.org/10.1289/ehp.5878.

18. Lawson CC, Whelan EA, Lividoti Hibert EN, Spiegelman D, Schernhammer ES, Rich-Edwards JW. Rotating Shift Work and Menstrual Cycle Characteristics. Epidemiology. 2011 May;22(3):305-12. http://dx.doi.org/10.1097/ EDE.0b013e3182130016.

19. Wan GH, Chung FF. Working Conditions Associated with Ovarian Cycle in a Medical Center Nurses: A Taiwan Study. Jpn J Nurs Sci. 2012 Jun;9(1):112-8. http://dx.doi. org/10.1111/j.1742-7924.2011.00191.x.

20. Lin CC, Huang CN, Hwang YH, Wang JD, Weng SP, Shie $\mathrm{RH}$, et al. Shortened Menstrual Cycles in Lcd Manufacturing Workers. Occup Med. 2013;63(1):45-52. http://dx.doi. org/10.1093/occmed/kqs172.

21. Attarchi M, Darkhi H, Khodarahmian M, Dolati M, Kashanian M, Ghaffari M, et al. Characteristics of Menstrual Cycle in Shift Workers. Glob J Health Sci. 2013 May;5(3):163-72.

22. Florack EI, Zielhuis GA, Rolland R. The Influence of Occupational Physical Activity on Menstrual Cycle and Fecundability. Epidemiology. 1994;5(1):14-8. http://dx.doi. org/10.1097/00001648-199401000-00004.

23. Messing K, Saurel-Cubizolles MJ, Bourgine M, Kaminski M. Factors Associated with Dysmenorrhea among Workers in French Poultry Slaugtherhouses and Canneries. J Occup Med. 1993;35(5):493-500.
24. Tissot F, Messing K. Perimenstrual Symptoms and Working Conditions among Hospital Workers in Quebec. Am J Ind Med. 1995;27(4):511-22. http://dx.doi.org/10.1002/ ajim. 4700270405 .

25. Harlow SD, Matanoski GM. The Association between Weight, Physical Activity, and Stress and Variation in the Length of the Menstrual Cycle. Am J Epidemiol. 1991;133(1):38-49.

26. Caruso CC. Possible Broad Impacts of Long Work Hours. Ind Health. 2006 Oct;44(4):531-6. http://dx.doi.org/10.2486/ indhealth.44.531.

27. Enea C, Boisseau N, Fargeas-Gluck MA, Diaz V, Dugue B. Circulating Androgens in Women: Exercise-Induced Changes. Sports Med. 2011 Jan 1;41(1):1-15. http://dx.doi. org/10.2165/11536920-000000000-00000.

28. Louis GM, Lum KJ, Sundaram R, Chen Z, Kim S, Lynch $\mathrm{CD}$, et al. Stress Reduces Conception Probabilities across the Fertile Window: Evidence in Support of Relaxation. Fertil Steril. 2011 Jun;95(7):2184-9. http://dx.doi.org/10.1016/j. fertnstert.2010.06.078.

29. Scott LD, Hofmeister N, Rogness N, Rogers AE. An Interventional Approach for Patient and Nurse Safety: A Fatigue Countermeasures Feasibility Study. Nurs Res. 2010 Jul-Aug;59(4):250-8. http://dx.doi.org/10.1097/ NNR.0b013e3181de9116.

30. Rich-Edwards JW, Goldman MB, Willett WC, Hunter DJ, Stampfer MJ, Colditz GA, et al. Adolescent Body Mass Index and Infertility Caused by Ovulatory Disorder. Am J Obstet Gynecol. 1994 Jul;171(1):171-7. http://dx.doi. org/10.1016/0002-9378(94)90465-0.

31. Colditz GA, Martin P, Stampfer MJ, Willett WC, Sampson L, Rosner B, et al. Validation of Questionnaire Information on Risk Factors and Disease Outcomes in a Prospective Cohort Study of Women. Am J Epidemiol. 1986 May;123(5):894-900.

32. Jukic AM, Weinberg CR, Wilcox AJ, McConnaughey DR, Hornsby P, Baird DD. Accuracy of Reporting of Menstrual Cycle Length. Am J Epidemiol. 2008 Jan 1;167(1):25-33. http://dx.doi.org/10.1093/aje/kwm265.

33. Small CM, Manatunga AK, Marcus M. Validity of Self-Reported Menstrual Cycle Length. Ann Epidemiol. 2007 Mar;17(3):163-70. http://dx.doi.org/10.1016/j. annepidem.2006.05.005.

Received for publication: 4 August 2014 